\title{
Hypolipidemic activity of Pleurotus florida against Triton WR 1339 induced Hyperlipidemia ${ }^{\dagger}$
}

\author{
Greeshma P.V. ${ }^{1, *}$, Steffy Julius ${ }^{2}$, Janardhanan K.K. ${ }^{3}$ \\ 1 Assistant Professor, St. Mary's College, Thrissur \\ St. Peter's College Kolenchery, Ernakulam \\ Professor, Amala Cancer Research Centre, Thrissur \\ * Correspondence: greeshmamicro@gmail.com; \\ $\uparrow$ Presented at International e-Conference on Bioengineering for Health and Environment (ICBHE 2020)
}

Received: 5.07.2020; Revised: 10.07.2020; Accepted: 12.07.2020; Published: 15.07.2020

\begin{abstract}
Pleurotus florida (Oyster mushroom) belongs to the family Pleurotaceae and is one of the widely used edible mushrooms. The aqueous ethanolic extract of the fruiting body of P.florida was evaluated for hypolipidemic activity. Hyperlipidemia was induced with the help of Triton WR 1339 $(100 \mathrm{mg} / \mathrm{Kg}$ b.w.) administered via intraperitoneal injection. Atorvastatin $(2.5 \mathrm{mg} / \mathrm{Kg} \mathrm{b.w})$ was used as the standard drug. Different concentrations of aqueous ethanolic extract of P.florida (500, 250, and $100 \mathrm{mg} / \mathrm{Kg}$ b.w) were given orally before triton administration. The serum lipid profile was assayed and showed significant hypolipidemic activity compared to the control group (Triton alone). The activity of HMG CoA reductase was assayed using hydroxylamine hydrochloride. Hepatic HMG CoA reductase activity was significantly decreased in the treated group as compared to control. The inhibition of lipid peroxidation was also assayed. A significant reduction in lipid peroxidation was seen in groups treated with extract compared to control. Lovastatin was also isolated from fruiting bodies and culture filtrate and screened using Thin Layer Chromatography. Lovastatin (sigma) was used as the standard. The finding suggests the significant hypolipidemic activity of the aqueous ethanolic extract of P.florida.
\end{abstract}

Keywords: Hypolipidemia; Triton WR 1339; HMG CoA Reductase; Pleurotus florida.

(C) 2020 by the authors. This article is an open-access article distributed under the terms and conditions of the Creative Commons Attribution (CC BY) license (https://creativecommons.org/licenses/by/4.0/).

\section{Funding}

This research received no external funding.

\section{Acknowledgments}

This research has no acknowledgment.

\section{Conflicts of Interest}

The authors declare no conflict of interest 